\title{
Reseña de la Jurisprudencia de la Corte Interamericana de Derechos Humanos (2010) ${ }^{1}$
}

Este comentario, junto a los documentos que analiza, está disponible en www.anuariocdh.uchile.cl
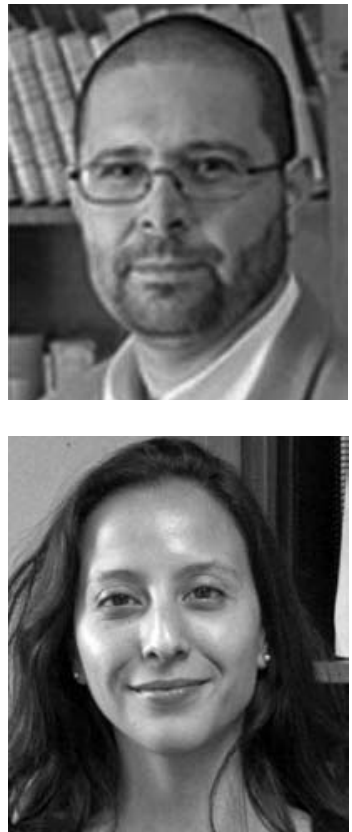

\section{Claudio Nash Rojas}

Licenciado en Ciencias Jurídicas y Sociales (Universidad de Chile, 1998) y Doctor en Derecho (Universidad de Chile, 2008). Subdirector del Centro de Derechos Humanos de la Facultad de Derecho de la Universidad de Chile y Director del Programa "Estado de Derecho y Derechos Humanos" del mismo Centro.

cnash@derecho.uchile.cl

\section{Claudia Sarmiento Ramírez}

Licenciada en Ciencias Jurídicas y Sociales por la Facultad de Derecho de la Universidad de Chile. Investigadora del Programa "Mujeres y Derechos Humanos" y editora del Anuario de Derechos Humanos, del Centro de Derechos Humanos $(\mathrm{CDH})$ de la misma Casa de Estudios.

csarmien@derecho.uchile.cl

\section{RESUMEN}

El artículo revisa críticamente las sentencias dictadas por la Corte Interamericana de Derechos Humanos durante el año 2010 que, a juicio de los autores, serán relevantes para la región. A partir del análisis de las sentencias se examina, por una parte, la calificación de la violencia sexual como una forma de tortura, el reconocimiento de su gravedad y sus formas de su acreditación, y por otra, las obligaciones internacionales de los Estados en relación a los derechos de las/los migrantes. Igualmente se analizan sentencias que marcarán tendencias en el sistema respecto del derecho a la libertad de expresión y su relación con el "derecho a la verdad", el derecho al reconocimiento de la personalidad jurídica, los derechos políticos y la protección de la honra y dignidad.

La Corte Interamericana de Derechos Humanos ("Corte" o "Corte Interamericana") fue establecida en el sistema interamericano por la Convención Americana sobre Derechos Humanos ("CADH"

1 Los autores agradecen los comentarios y la edición del texto de la investigadora del Centro de Derechos Humanos Valeska David. 
o "Convención Americana") ${ }^{2}$. Sus funciones son dos: (a) resolver los casos contenciosos sobre una presunta violación a la Convención Americana de un Estado parte, y (b) emitir opiniones consultivas.

Conforme con lo preceptuado en el artículo 63 de la CADH, la Corte establecerá si ha habido una violación de alguno de los derechos o libertades consagrados en la Convención Americana. Además, determinará la forma en que el Estado debe restituir la situación al estado anterior a la comisión del ilícito y, en caso de que esto no sea posible, determinará la manera en que se reparará el mal causado. Conforme con lo dispuesto en el artículo 68.1 de la Convención Americana, las partes se comprometen a cumplir las decisiones de la Corte.

Durante el año 2010 la Corte dictó 9 sentencias definitivas ${ }^{3}$.

En este artículo reseñaremos algunas de las sentencias definitivas dictadas por la Corte que pueden ser de relevancia para nuestra región. Nos referiremos a dos aspectos generales que surgen de la jurisprudencia de este año: por una parte, la calificación de la violencia sexual como una forma de tortura, el reconocimiento de su gravedad y sus formas de su acreditación; y por otra, las obligaciones internacionales de los Estados en relación a los derechos de las/los migrantes. En la segunda parte analizaremos algunas sentencias que marcarán tendencias en el sistema respecto del derecho a la libertad de expresión y su relación con el "derecho a la verdad", el derecho al reconocimiento de la personalidad jurídica, los derechos políticos y la protección de la honra y dignidad.

\section{Aspectos generales}

\section{a. Migrantes}

El tema de las migraciones y, en particular, el de los migrantes indocumentados, es una de las cuestiones que han ido copando la agenda en nuestra región. La tensión que se produce muchas veces entre el legítimo derecho de los Estados de regular la inmigración y la obligación de respetar los derechos humanos no siempre es una cuestión fácil de resolver. De ahí que no es de extrañar que este sea un tema al que la Corte ha dedicado su atención. El primer pronunciamiento fue a través de la conocida Opinión Consultiva dictada en 2003, relativa a la situación de los trabajadores migrantes. En 2010, la Corte ha vuelto sobre el tema, pero ahora en sede contenciosa. En el caso Vélez Loor vs. Panamá ${ }^{4}$ la Corte fija ciertos estándares generales sobre la materia, que es relevante destacar en esta reseña jurisprudencial.

La sentencia divide su razonamiento en tres fases: la primera, es fijar el rol de los derechos humanos como un límite a las políticas públicas; luego, determina el contexto en el que se encuentra la persona que ha visto afectados sus derechos; y finalmente, analiza cada derecho involucrado a la luz de estas consideraciones de contexto.

Al momento de fijar el rol de los derechos humanos como un límite a las políticas públicas, la Corte señala:

2 La Convención Americana sobre Derechos Humanos se adoptó en 1969 durante la Conferencia Especializada de Derechos Humanos, realizada en San José, Costa Rica.

3 Las sentencias de la Corte Interamericana de Derechos Humanos están disponibles íntegramente en su página Web http:// www.corteidh.or.cr/index.cfm. Para un análisis de cada uno de los fallos se sugiere revisar el Boletín de la Jurisprudencia de la Corte Interamericana de Derechos Humanos, disponible en http://www.cdh.uchile.cl/

4 Caso Vélez Loor Vs. Panamá. Excepciones Preliminares, Fondo, Reparaciones y Costas. Sentencia de 23 de noviembre de 2010 Serie C No. 218. 
Este Tribunal ya ha manifestado que, en el ejercicio de su facultad de fijar políticas migratorias, los Estados pueden establecer mecanismos de control de ingreso a su territorio y salida de él con respecto a personas que no sean nacionales suyas, siempre que dichas políticas sean compatibles con las normas de protección de los derechos humanos establecidas en la Convención Americana. En efecto, si bien los Estados guardan un ámbito de discrecionalidad al determinar sus políticas migratorias, los objetivos perseguidos por las mismas deben respetar los derechos humanos de las personas migrantes ${ }^{5}$.

Al caracterizar esta situación como estructural, la Corte hace un interesante análisis de cuáles son los elementos que configuran una violación con un fuerte componente estructural:

En este sentido, la Corte ha establecido que de las obligaciones generales de respetar y garantizar los derechos, derivan deberes especiales, determinables en función de las particulares necesidades de protección del sujeto de derecho, ya sea por su condición personal o por la situación específica en que se encuentre. A este respecto, los migrantes indocumentados o en situación irregular han sido identificados como un grupo en situación de vulnerabilidad, pues "son los más expuestos a las violaciones potenciales o reales de sus derechos" y sufren, a consecuencia de su situación, un nivel elevado de desprotección de sus derechos y "diferencias en el acceso [...] a los recursos públicos administrados por el Estado [con relación a los nacionales o residentes]". Evidentemente, esta condición de vulnerabilidad conlleva "una dimensión ideológica y se presenta en un contexto histórico que es distinto para cada Estado, y es mantenida por situaciones de jure (desigualdades entre nacionales y extranjeros en las leyes) y de facto (desigualdades estructurales)". Del mismo modo, los prejuicios culturales acerca de los migrantes permiten la reproducción de las condiciones de vulnerabilidad, dificultando la integración de los migrantes a la sociedad. Finalmente, es de notar que las violaciones de derechos humanos cometidas en contra de los migrantes quedan muchas veces en impunidad debido, inter alia, a la existencia de factores culturales que justifican estos hechos, a la falta de acceso a las estructuras de poder en una sociedad determinada, y a impedimentos normativos y fácticos que tornan ilusorios un efectivo acceso a la justicia ${ }^{6}$.

Esta mirada que atiende al contexto se relaciona con la interpretación de los derechos afectados, en tanto dicho ejercicio hermenéutico no puede soslayar cuál es la real condición y circunstancias del titular del derecho que se reclama. De esta forma, el paradigma de la justicia ciega a los justiciables ha cedido espacio a la necesidad de asegurar, en la práctica, el goce y ejercicio igualitario de los derechos de todas las personas, atendiendo a cuál es la situación desde la que intentan ejercer sus derechos ${ }^{7}$.

Asimismo, es interesante el fallo en su tercera parte, esto es, en el análisis de derechos específicos, ya que en este apartado se preocupa de analizar de qué manera cada derecho involucrado en los casos de procesos de expulsión de migrantes es aplicable en la especie. Se reiteran estándares en materia de libertad personal, debido proceso e integridad personal. Del razonamiento de la Corte se desprende la necesidad de adoptar medidas especiales, atendidas las condiciones de especial vulnerabilidad en el goce de sus derechos en que se encuentran las personas en situación de migración irregular.

Ibídem, párr. 97.

Ibídem, párr. 98.

7 CENTRO DE DERECHOS HUMANOS, Facultad de Derecho, Universidad de Chile. Boletín de Jurisprudencia de la Corte Interamericana de Derechos Humanos 1/2009. Disponible en http://www.estadodederechocdh.uchile.cl/media/ noticias/boletin.pdf 
En relación con la libertad personal, la Corte se preocupa de establecer los presupuestos mínimos que debe cumplir la detención en el contexto de una situación migratoria irregular. En particular, se refiere a la privación de libertad y al control judicial de la misma ${ }^{8}$ y desarrolla con algún detalle la prohibición de la privación arbitraria de la libertad ${ }^{9}$. En este punto, la Corte no hace sino reiterar la obligación del Estado de respetar los estándares convencionales a las personas migrantes, aun cuando su estatus migratorio no se encuentre regularizado.

Un tema que preocupa especialmente a la Corte es la legitimidad de la imposición de una medida privativa de la libertad de carácter punitivo, por el incumplimiento de leyes migratorias. A este respecto la Corte señala que el Estado tiene un rango amplio para determinar los motivos por los cuales una persona puede ser privada de su libertad ${ }^{10}$ y parece legítimo que el control de la migración sea una causal que permita este tipo de medida restrictiva de la libertad personal ${ }^{11}$. Pero esto no implica que el Estado pueda adoptar medidas de restricción en forma discrecional, sino que es necesario que justifique la necesariedad, idoneidad y proporcionalidad de la medida. En el caso concreto que analiza, la Corte estima que "[E]n el presente caso, la Corte considera que la finalidad de imponer una medida punitiva al migrante que reingresara de manera irregular al país tras una orden de deportación previa no constituye una finalidad legítima de acuerdo a la Convención"12. En cuanto a la proporcionalidad de una medida punitiva de privación de libertad, como medida para la regulación de la migración ilegal, la Corte señala que "serán arbitrarias las políticas migratorias cuyo eje central es la detención obligatoria de los migrantes irregulares, sin que las autoridades competentes verifiquen en cada caso en particular, y mediante una evaluación individualizada, la posibilidad de utilizar medidas menos restrictivas que sean efectivas para alcanzar aquellos fines" ${ }^{\prime 13}$. Este tipo de medidas provoca privaciones arbitrarias de la libertad, lo que no es legítimo conforme a las obligaciones convencionales del Estado (artículo 7.3 de la CADH).

Un desarrollo más interesante hace la Corte al momento de analizar el debido proceso. Aquí la Corte se preocupa de establecer presupuestos mínimos que debe cumplir el proceso de expulsión en el contexto de una situación migratoria irregular. En primer lugar, la Corte aclara la plena aplicabilidad de las garantías de un debido proceso a estos procedimientos migratorios, aunque estos sean regulados como procedimientos de tipo administrativo por parte de los Estados. De esta forma, la Corte fija un doble carácter; por una parte, el deber de respetar el debido proceso en procedimientos de cualquier naturaleza jurídica que afecten los derechos fundamentales de las personas ${ }^{14}$ y, por otra, determina la aplicación de las "garantías mínimas" a los procesos administrativos sancionatorios ${ }^{15}$.

En segundo lugar, la Corte establece que el derecho de defensa, ejercido en condiciones de igualdad, es un derecho básico en los casos relativos a migrantes e implica "(...) tratar al individuo en todo momento como un verdadero sujeto del proceso, en el más amplio sentido de este concepto, y no simplemente como objeto del mismo" ${ }^{\prime 16}$. Además, la Corte, atendidas las

\footnotetext{
Caso Vélez Loor Vs. Panamá, párrs. 105-108.

Ibídem, párrs. 116-118.

o Ibídem, párr. 168.

11 La Corte sí indica qué objetivos están autorizados para privar de libertad a estas personas: "asegurar la comparecencia de la persona al proceso migratorio o para garantizar la aplicación de una orden de deportación" (Ibídem, párr. 169).

12 Ibídem, párr. 169.

13 Ibídem, párr. 171.

14 Ibídem, párr. 141.

15 Ibídem, párr. 142.

16 Ibídem, párr. 145.
} 
particulares circunstancias de las personas migrantes en situación irregular, parece pronunciarse -aunque de una manera indirecta y algo tímida - a favor de una asistencia letrada en el ejercicio del derecho de defensa (aunque la Convención Americana permite la autodefensa). Lo que es claro en el razonamiento de la Corte es el deber que tienen los Estados de prestar asistencia jurídica gratuita en los procedimientos administrativos o judiciales que puedan significar la deportación, expulsión o privación de libertad ${ }^{17}$.

En tercer lugar, la Corte reitera su jurisprudencia constante acerca del derecho a la información y acceso efectivo a la asistencia consular ${ }^{18}$. En efecto, la sentencia no solo reitera que el extranjero que es privado de libertad y sometido a un procedimiento que puede traer aparejada la violación de sus derechos tiene derecho a ser informado de que le asiste el derecho a comunicarse con su consulado, sino que dicha comunicación debe ser efectiva y por tanto, debe verse reflejada en su derecho a defensa ${ }^{19}$. En este caso, el peticionario había estado en comunicación con su consulado, pero esto no pudo materializarse en la defensa ya que no fue notificado de su derecho a contactarse con su consulado desde el comienzo del proceso, por lo que la Corte estima que el Estado incumplió con su obligación de garantizar un debido proceso ${ }^{20}$.

Sin referirse a la particular situación de los migrantes, la Corte aclara, además, algunas cuestiones relativas al derecho a recurrir del fallo que impone sanciones, ante un órgano superior. La Corte aclara que esto debe ser analizado en el ámbito del art. 8.2.h y no del artículo 25 y luego se pronuncia sobre los requisitos de fondo y la efectividad de esta segunda instancia: "Para que haya una verdadera revisión de la sentencia, en el sentido requerido por la Convención, es preciso que el tribunal superior reúna las características jurisdiccionales que lo legitiman para conocer del caso concreto. Sobre este punto, si bien los Estados tienen cierta discrecionalidad para regular el ejercicio de ese recurso, no pueden establecer restricciones o requisitos que infrinjan la esencia misma del derecho a recurrir del fallo. La posibilidad de "recurrir del fallo" debe ser accesible, sin requerir mayores complejidades que tornen ilusorio este derecho" ${ }^{\prime 2}$.

Asimismo, la Corte reitera aquí algunas cuestiones que son ya parte de su jurisprudencia constante en materia de personas privadas de libertad y particularmente, de condiciones carcelarias ${ }^{22}$. Establece el deber del Estado de asegurar condiciones de detención compatibles con la dignidad de los seres humanos ${ }^{23}$. En este caso se preocupa, en particular, del deber del Estado de asegurar condiciones mínimas de detención: suministro de agua potable y asistencia médica ${ }^{24}$. El incumplimiento de estos mínimos le permite a la Corte calificar las condiciones de detención indignas como tratos crueles, inhumanos y degradantes ${ }^{25}$.

Un aspecto específico de la situación de las personas migrantes privadas de libertad, es la obligación del Estado de mantener a estas personas en recintos separados de aquellos destinados a las personas sujetas a una sanción penal. A juicio de la Corte, "este principio de separación atiende,

17 Ibídem, párr. 146.

18 Corte IDH. El Derecho a la Información sobre la Asistencia Consular en el Marco de las Garantías del Debido Proceso Legal. Opinión Consultiva OC-16/99 del 1 de octubre de 1999. Serie A No. 16.

19 Caso Vélez Loor Vs. Panamá, párrs. 151 a 159.

20 Ibídem, párr. 160.

21 Ibídem, párr. 179.

22 Un buen resumen en Corte IDH. Caso Montero Aranguren y otros (Retén de Catia) Vs. Venezuela. Excepción Preliminar, Fondo, Reparaciones y Costas. Sentencia de 5 de julio de 2006. Serie C No. 150.

23 Caso Vélez Loor Vs. Panamá, párrs. 198 y ss.

24 Ibídem, párrs. 216-222.

25 Ibídem, párr. 227. 
ciertamente, a las diferentes finalidades de la privación de libertad" y "[P]or consiguiente, el Tribunal considera que los Estados deben disponer de establecimientos públicos separados, específicamente destinados a este fin y, en caso de que el Estado no cuente con dichas facilidades, deberá disponer de otros lugares, los cuales en ningún caso podrán ser los centros penitenciarios" 26 . Pero la Corte va más allá y determina ciertas condiciones materiales con las que deben contar estos recintos:

"Si bien la privación de libertad trae a menudo, como consecuencia ineludible, la afectación del goce de otros derechos humanos además del derecho a la libertad personal, en caso de personas privadas de libertad exclusivamente por cuestiones migratorias, los lugares de detención deben encontrarse diseñados a los fines de garantizar "condiciones materiales y un régimen adecuado para su situación legal, y cuyo personal esté debidamente cualificado", evitando en lo posible la desintegración de los núcleos familiares. En consecuencia, el Estado está obligado a adoptar determinadas medidas positivas, concretas y orientadas, para garantizar no sólo el goce y ejercicio de aquellos derechos cuya restricción no resulta un efecto colateral de la situación de privación de la libertad, sino también para asegurar que la misma no genere un mayor riesgo de afectación a los derechos, a la integridad y al bienestar personal y familiar de las personas migrantes" 27 .

\section{b. Violencia sexual}

En los casos Fernández Ortega ${ }^{28}$ y Rosendo Cantú ${ }^{29}$, ambos contra México, la Corte Interamericana analizó el cumplimiento de las obligaciones internacionales del Estado, por su respuesta ante la violación sexual cometida por militares en contra de las víctimas del caso.

En ambas sentencias las víctimas eran mujeres indígenas pertenecientes a la etnia Me' phaa; vivían en zonas rurales de difícil acceso en el Estado de Guerrero, donde existe una fuerte presencia militar que busca reprimir el crimen organizado en la zona; eran mujeres jóvenes ${ }^{30}$ y casi no hablaban castellano. Igualmente, ambas fueron víctimas de violación sexual por parte de agentes militares, en el contexto de violentas interrogaciones ${ }^{31}$, y en ninguno de estos casos se estableció la responsabilidad de los culpables.

Las dificultades en la búsqueda de justicia que ambas enfrentaron también fueron las mismas. En una primera instancia, las autoridades se rehusaron a recibir sus denuncias, no se les prestó atención médica apropiada para obtener y resguardar las pruebas que permitieran establecer las responsabilidades penales de los violadores, ni tratamientos fisiológicos y psicológicos que procuraran sanar sus heridas, y sus causas pasaron del fuero civil al militar. Tanto la señora Fernández Ortega como la señora Rosendo Cantú experimentaron un profundo sufrimiento, miedo y vergüenza a causa de la violación sexual y la falta de respuesta de las autoridades judiciales civiles y militares.

La Corte resolvió en ambos casos que el Estado era responsable por la violación, inter alia, de sus obligaciones de respeto y garantía (artículo 1.1) de los derechos a la integridad personal, a la dignidad y a la vida privada, consagrados, respectivamente, en los artículos 5.2, 11.1 y 11.2 de la

26 Ibídem, párr. 208.

27 Ibídem, párr. 209.

28 Caso Fernández Ortega y otros. Vs. México. Excepción Preliminar, Fondo, Reparaciones y Costas. Sentencia de 30 de agosto de 2010 Serie C No. 215.

29 Caso Rosendo Cantú y otra Vs. México. Excepción Preliminar, Fondo, Reparaciones y Costas. Sentencia de 31 de agosto de 2010 Serie C No. 216.

30 Valentina Rosendo Cantú tenía 17 años e Inés Fernández Ortega tenía 25 al momento del ataque.

31 Estos ataques incluso son cercanos temporalmente. La señora Rosendo Cantú fue atacada el 16 de febrero de 2002 y la señora Fernández Ortega el 22 de marzo de 2002. 
Convención Americana y de los artículos 1, 2 y 6 de la Convención Interamericana para Prevenir y Sancionar la Tortura, así como por el incumplimiento del deber establecido en el artículo 7.a de la Convención Interamericana para Prevenir, Sancionar y Erradicar la Violencia contra la Mujer ${ }^{32}$. Es decir, la Corte calificó la violación sexual que sufrieron las víctimas del caso a manos de militares y la posterior negligencia en el esclarecimiento de las responsabilidades como tortura.

Esta no es la primera vez que la Corte ha debido analizar si la conducta de un Estado ante la violencia sexual ${ }^{33}$ es compatible o no con sus obligaciones convencionales. No obstante, es la primera vez que la califica como tortura.

La prohibición absoluta de la tortura es una norma fundamental del derecho internacional de los derechos humanos. Calificar la violación sexual como tortura implica reconocer que esta es una conducta inaceptable que no admite justificación bajo ninguna circunstancia. Esta calificación sigue la tendencia de los tribunales internacionales para la ex Yugoslavia ${ }^{34}$ y Ruanda ${ }^{35}$, que ya en el año 1998 habían calificado la violencia sexual como un crimen de lesa humanidad ${ }^{36}$.

Con certeza, la calificación como tortura de la violación sexual es el resultado de un lento, pero progresivo avance en la percepción de la Corte acerca de la gravedad y naturaleza de la violencia contra las mujeres, particularmente de la violencia sexual ${ }^{37}$. Los casos Fernández y Rosendo son el más claro reflejo de ese cambio ${ }^{38}$. Prueba de ello es que en el año 1997, respecto de la violación sexual denunciada por la Señora Loayza Tamayo, la Corte resolvió que "[...] dada la naturaleza del hecho, no está en condiciones de darlo por probado"39. A pesar de contar con igual sustento probatorio respecto de los demás ataques denunciados por la víctima, como la incomunicación y otros actos de violencia, solicitó un estándar de prueba distinto respecto de la violación sexual por la naturaleza del hecho.

En los casos en comento, la defensa del Estado se allanó parcialmente por las negligencias en la investigación ${ }^{40}$, pero indicó que si bien lamentaba "las consecuencias que genera una violación sexual tanto en las propias víctimas como en sus familiares cercanos [...] no ha podido

32 Caso Fernández Ortega, párr. 131; Caso Rosendo Cantú, párr. 182.

33 En este sentido ver Corte IDH. Caso del Penal Miguel Castro Castro Vs. Perú. Fondo, Reparaciones y Costas. Sentencia de 25 de noviembre de 2006. Serie C No. 160; Caso De la Masacre de las Dos Erres Vs. Guatemala. Excepción Preliminar, Fondo, Reparaciones y Costas. Sentencia de 24 de noviembre de 2009. Serie C No. 211; Caso González y otras ("Campo Algodonero") Vs. México. Excepción Preliminar, Fondo, Reparaciones y Costas. Sentencia de 16 de noviembre de 2009. Serie C No. 205.

34 Tribunal Penal Internacional para la ex Yugoslavia. Caso № IT-95-17/1-T. Fiscal vs. Anto Furundziya. Sentencia del 10 de diciembre de 1998.

35 Tribunal Penal Internacional para Ruanda. Caso No ICTR-96-4-T. Fiscal vs. Jean Paul Akayesu. Sentencia del 2 de septiembre de 1998.

36 Para una revisión de estos casos puede analizarse DAVIS, Patricia H. The politics of Prosecuting Rape as a War Crime. [Consultado en HeinOnline el 22 de marzo de 2011]; y PALACIOS, Patricia. El tratamiento de la violencia de género en la Organización de Naciones Unidas. Centro de Derechos Humanos, Facultad de Derecho, Universidad de Chile. Disponible en línea en http://www.programamujerescdh.cl/media/publicaciones/tratamiento_violencia_genero.pdf

37 Sobre la evolución de la perspectiva de género en la jurisprudencia de la Corte Interamericana ver PALACIOS, Patricia. The Path to Gender Justice in the Inter-American Court of Human Rights. Texas Journal of Women and the Law, 17(2), primavera 2008.

38 “[...] [C]omo lo señala la Convención de Belém do Pará, que la violencia contra la mujer no sólo constituye una violación de los derechos humanos, sino que es 'una ofensa a la dignidad humana y una manifestación de las relaciones de poder históricamente desiguales entre mujeres y hombres', que 'trasciende todos los sectores de la sociedad independientemente de su clase, raza o grupo étnico, nivel de ingresos, cultura, nivel educacional, edad o religión y afecta negativamente sus propias bases'". Caso Fernández Ortega, párr. 118.

39 Corte IDH. Caso Loayza Tamayo Vs. Perú. Fondo. Sentencia de 17 de septiembre de 1997. Serie C No. 33. Párr. 58.

40 Caso Fernández Ortega, párr. 135 y Caso Rosendo Cantú, párrs. 16 y 23. 
ser acreditado el delito ni sus responsables, por lo que [...] no puede reconocer y aceptar que el derecho a la integridad personal y a la honra y dignidad [...] han sido violados $[\ldots]^{\prime \prime 4}$. Acto seguido, manifestó que correspondía a la Comisión y a los Representantes de la Peticionaria acreditar la violación.

La Corte -a diferencia del caso Loayza Tamayo- desechó esta defensa, en primer lugar, otorgando a la declaración de la víctima un valor superlativamente superior al que le daba el Estado. En este sentido, es destacable que la Corte considerara que "resulta evidente que la violación sexual es un tipo particular de agresión que, en general, se caracteriza por producirse en ausencia de otras personas más allá de la víctima y el agresor o los agresores. Dada la naturaleza de esta forma de violencia, no se puede esperar la existencia de pruebas gráficas o documentales y, por ello, la declaración de la víctima constituye una prueba fundamental sobre el hecho" ${ }^{\prime 2}$. La Corte, además, contextualizó la situación particular en la que se encontraban ambas peticionarias, poniendo en evidencia que a pesar de todas las barreras que cada una debió enfrentar -condiciones de aislamiento geográfico y barreras idiomáticas- y las potenciales consecuencias perniciosas que podrían experimentar -repercusiones negativas en su medio social y cultural y posibles represalias de parte de los efectivos militares que estaban permanentemente apostados en la zona en la que ellas vivían- sus relatos fueron constantes y su búsqueda de justicia también ${ }^{43}$.

En segundo lugar, y destacando las falencias en la investigación imputables al Estado, la Corte indicó que "el Estado no puede justificarse con base, exclusivamente, en el desconocimiento de si la violación había existido y su autoría, cuando ello es consecuencia de sus propios errores o falencias [...] Concluir lo contrario implicaría permitir al Estado ampararse en la negligencia e inefectividad de la investigación penal para sustraerse de su responsabilidad por la violación de derechos reconocidos por la Convención Americana" ${ }^{44}$.

Igualmente, la Corte permanentemente contextualizó la violación sexual y la situación de las víctimas, además de reconocer que este delito no es asimilable por su gravedad y sus implicancias ${ }^{45}$ a uno de tipo común. Este ejercicio fue fundamental para desechar los argumentos del Estado en los que estaba implícito que existía una falta de colaboración de las víctimas en el esclarecimiento de las responsabilidades en el caso, o la verosimilitud de sus denuncias ${ }^{46}$. De esta forma, la Corte transitó

41 Caso Fernández Ortega, párr. 95 y Caso Rosendo Cantú, párr. 85.

42 Caso Fernández Ortega, párr. 100 y Caso Rosendo Cantú, párr. 89.

43 Caso Rosendo Cantú, párr. 93. La Corte también destacó que la condición de indígenas de las víctimas era un factor que agudizaba su situación de vulnerabilidad. Específicamente señaló que "[e]n general, la población indígena se encuentra en una situación de vulnerabilidad, reflejada en diferentes ámbitos, como la administración de justicia y los servicios de salud, particularmente, por no hablar español y no contar con intérpretes, por la falta de recursos económicos para acceder a un abogado, trasladarse a centros de salud o a los órganos judiciales y también por ser víctimas de prácticas abusivas o violatorias del debido proceso. Lo anterior ha provocado que integrantes de las comunidades indígenas no acudan a los órganos de justicia o instancias públicas de protección de los derechos humanos por desconfianza o por miedo a represalias, situación que se agrava para las mujeres indígenas puesto que la denuncia de ciertos hechos se ha convertido para ellas en un reto que requiere enfrentar muchas barreras, incluso el rechazo por parte de su comunidad y otras "prácticas dañinas tradicionales". Caso Fernández Ortega, párr. 78. Caso Rosendo Cantú, párr. 70.

44 Caso Fernández Ortega, párr. 116 y Caso Rosendo Cantú, párr. 104.

45 “[...] Este Tribunal ha reconocido que la violación sexual es una experiencia sumamente traumática que tiene severas consecuencias y causa gran daño físico y psicológico que deja a la víctima "humillada física y emocionalmente", situación difícilmente superable por el paso del tiempo, a diferencia de lo que acontece en otras experiencias traumáticas". Caso Fernández Ortega, párr. 124. En relación a la discusión que existe dentro de los feminismos sobre la posibilidad de consentimiento efectivo en las relaciones sexuales en un contexto de dominación patriarcal ver ESTRICH, Susan. Violación. DI CORLETO, Julieta (comp.). Justicia, género y violencia. Buenos Aires, Libraria, Red ALAS, 2010 , pp. 57-84.

46 Específicamente, el Estado hizo referencia en el caso Fernández a las “imprecisiones del relato" (párr. 112), y en Rosendo Cantú a la omisión de la víctima de declarar la violación ante el médico que la trató por primera vez y su falta de concurrencia a rendir declaración ante las autoridades militares (párr. 95 y 190). 
desde un paradigma ciego a las circunstancias de la víctima, a uno que valida y explica cómo el miedo y la vergüenza pueden mermar o condicionar su participación en la investigación, sin que esto signifique que aquella está mintiendo o que de alguna manera consintió en el ataque ${ }^{47}$.

Es esta perspectiva centrada en la situación de la víctima la que debe permear la forma en que los Estados enfocan sus procedimientos judiciales frente a los casos de violación sexual. En las reparaciones, la Corte exhorta al Estado precisamente a impulsar un cambio en la cultura en el personal sanitario y del poder judicial ${ }^{48}$, donde destaca la incorporación de la perspectiva de género y los derechos humanos de las mujeres. Si bien la Corte también hace una referencia general a la educación en derechos humanos al interior del Ejército ${ }^{49}$, en instituciones ultramasculinizadas, donde los roles de género se definen en forma estática y apelando a las concepciones tradicionales donde lo masculino es fuerte y agresivo, y lo femenino pasivo y tolerante, no es raro encontrar mayor tolerancia y justificación a la violación ${ }^{50}$. Tampoco es extraño que la violación sexual sea vista como una falta disciplinaria y no como un delito grave. Por tanto, habría sido deseable que se hubieran dado pautas más claras para superar las estructuras de género que legitiman la subordinación de las mujeres.

\section{Análisis de Derechos}

\section{a. Libertad de expresión y derecho a la verdad}

Los casos de violaciones masivas y sistemáticas de derechos humanos ocurridas durante décadas en Latinoamérica, dio paso a procesos de justicia transicional en los cuales las sociedades debieron hacer frente a este particular tipo de violaciones de derechos humanos. En el sistema interamericano, la respuesta frente a las decisiones de los Estados que establecen límites a la investigación y sanción de las violaciones de derechos humanos se ha fundamentado en un "derecho a la verdad" que emana de las obligaciones generales del Estado de respeto y garantía de los derechos consagrados en la Convención Americana sobre Derechos Humanos. El derecho a la verdad ha sido desarrollado por la Corte Interamericana desde un doble punto de vista, como un derecho colectivo o social a conocer la verdad y como un derecho individual. La Corte ha señalado:

"Este Tribunal se ha referido en reiteradas ocasiones al derecho que asiste a los familiares de las víctimas de conocer lo que sucedió y de saber quiénes fueron los agentes del Estado responsables de los respectivos hechos. Tal como ha señalado la Corte, "la investigación de los hechos y la sanción de las personas responsables, [...] es una obligación que corresponde al Estado siempre que haya ocurrido una violación de los derechos humanos y esa obligación debe ser cumplida seriamente y no como una mera formalidad.

Esta medida no solo beneficia a los familiares de las víctimas sino también a la sociedad como un todo, de manera que al conocer la verdad en cuanto a tales crímenes tenga la capacidad de prevenirlos en el futuro" ${ }^{\prime 51}$.

47 Caso Rosendo Cantú, párrs. 95 y 190; Caso Fernández Ortega, párr. 206.

48 Caso Fernández Ortega, párrs. 253-260.

49 Ibídem, párrs. 261-262.

50 De hecho, en ambos casos podemos encontrar que los ataques se produjeron en contextos de ataques en bandas, donde el consentimiento de las mujeres era un factor irrelevante para efectos de acceder a ellas y al estatus que se deriva de reafirmar la heterosexualidad ver BAKER, Katharine K. Sex, rape and shame. Boston University Law Review 79: 663-716. Consultado en HeinOnline el 22 de marzo de 2011.

51 Caso 19 Comerciantes Vs. Colombia. Fondo, Reparaciones y Costas. Sentencia de 5 de julio de 2004. Serie C No. 109, párrs. 258 y 259. 
De esta forma, el derecho a la verdad encuentra su fundamento más sólido en la obligación del Estado de garantizar el pleno goce y ejercicio de los derechos humanos. La falta de conocimiento de la verdad impide la justicia y se crean situaciones de impunidad que permiten la repetición de estas violaciones y, por tanto, impiden una efectiva garantía de los derechos humanos.

En el caso Gomes Lund y Otros ("Guerrilha do Araguaia") vs. Brasil52, relativo a la desaparición forzada de un grupo de personas bajo la dictadura militar vivida por ese país en las décadas del '60 y '70, la Corte aborda este tema y agrega una arista interesante: el acceso a la información como parte del derecho a la libertad de expresión. En este caso se plantea la obligación que tiene el Estado de entregar toda la información que se encuentre en su poder para facilitar las investigaciones que permitan el establecimiento de la verdad en casos de graves violaciones de derechos humanos, sin que pueda excusarse en cuestiones como la seguridad, confidencialidad o secreto de Estado:

"Finalmente, el Tribunal también ha establecido que en casos de violaciones de derechos humanos, las autoridades estatales no se pueden amparar en mecanismos como el secreto de Estado o la confidencialidad de la información, o en razones de interés público o seguridad nacional, para dejar de aportar la información requerida por las autoridades judiciales o administrativas encargadas de la investigación o proceso pendientes" ${ }^{\prime 53}$.

Asimismo, la decisión de la entrega de la información no puede radicarse en un órgano implicado en los hechos investigados y con claro interés en el resultado de las investigaciones, sin que además se realicen las gestiones de buena fe para obtener dicha información:

"Asimismo, cuando se trata de la investigación de un hecho punible, la decisión de calificar como secreta la información y de negar su entrega jamás puede depender exclusivamente de un órgano estatal a cuyos miembros se les atribuye la comisión del hecho ilícito. De igual modo, tampoco puede quedar a su discreción la decisión final sobre la existencia de la documentación solicitada" 54 .

"Resulta esencial que, para garantizar el derecho a la información, los poderes públicos actúen de buena fe y realicen diligentemente las acciones necesarias para asegurar la efectividad de ese derecho, especialmente cuando se trata de conocer la verdad de lo ocurrido en casos de violaciones graves de derechos humanos como las desapariciones forzadas y la ejecución extrajudicial del presente caso" ${ }^{\prime \prime 5}$.

De esta forma, es interesante cómo un derecho que la Corte ha reconocido hace poco tiempo comienza a jugar un rol relevante en la protección de otros derechos humanos.

\section{b. Derecho al reconocimiento de la personalidad jurídica (artículo 3 de la Convención Americana sobre Derechos Humanos)}

En el caso Anzualdo Castro la Corte IDH ha dado un giro en su jurisprudencia relativa a desapariciones forzadas. A partir de este caso, la Corte incluye entre los derechos violados a raíz de dicho

52 Caso Gomes Lund y otros (Guerrilha do Araguaia) Vs. Brasil. Excepciones Preliminares, Fondo, Reparaciones y Costas. Sentencia de 24 de noviembre de 2010. Serie C No. 219.

53 Ibídem, párr. 202, primera parte.

54 Ibídem, párr. 202 segunda parte.

55 Ibídem, párr. 211. 
acto pluriofensivo, el derecho al reconocimiento de la personalidad jurídica ${ }^{56}$. Este novedoso cambio en su jurisprudencia ha sido ratificado, además, en el caso Radilla Pacheco ${ }^{57}$.

Debemos advertir, sin embargo, que este tema ha sido abordado de manera acotada en la jurisprudencia de la Corte IDH ${ }^{58}$. Asimismo, de los casos que ésta había conocido en materia de desaparición forzada y en los que se había planteado una posible violación al artículo 3, la Corte IDH había desechado dicha hipótesis en más de una ocasión ${ }^{59}$.

La interesante innovación en esta materia nos obliga a reflexionar acerca del contenido del derecho al reconocimiento de la personalidad jurídica y la interpretación que ha efectuado al respecto la Corte IDH:

"Este derecho representa un parámetro para determinar si una persona es titular o no de los derechos de que se trate, y si los puede ejercer, por lo que desconocer aquel reconocimiento hace al individuo vulnerable frente al Estado o particulares. De este modo, el contenido del derecho al reconocimiento de la personalidad jurídica refiere al correlativo deber general del Estado de procurar los medios y condiciones jurídicas para que ese derecho pueda ser ejercido libre y plenamente por sus titulares" 60 .

Uno de los mayores riesgos de esta interpretación -que la ha hecho acreedora de varias críticas ${ }^{61}$ consiste en desdibujar el contenido jurídico propio del derecho consagrado en el artículo 3. En este sentido, se señala que el fenómeno que pretende atribuirse a una violación del reconocimiento de la personalidad jurídica, ya se encuentra cubierto por la vulneración de otros derechos, tales como el derecho a la vida, a la integridad, a la libertad y a un recurso efectivo, cuya concurrencia simultánea ha sido reconocida como una peculiaridad de las desapariciones forzadas.

56 Caso Anzualdo Castro vs. Perú, Sentencia de 22 de septiembre de 2009, Serie C No. 202, párr. 101. Cabe precisar que, anteriormente, la Corte había declarado la violación del artículo 3, pero sólo como consecuencia del reconocimiento de responsabilidad efectuado por el Estado en los casos Trujillo Oroza vs. Bolivia, Sentencia de 26 de enero de 2000 , Serie C No. 64 y Benavides Cevallos vs. Ecuador, Sentencia de 19 de junio de 1998, Serie C No. 38. Sin embargo, en el Caso Ticona Estrada y otros vs. Bolivia, Sentencia de 27 de noviembre de 2008, Serie C No. 191, en que el Estado también se había allanado, la Corte rechazó la violación del artículo3 de la Convención.

57 Caso Radilla Pacheco vs. México, Sentencia de 23 de noviembre de 2009, Serie C No. 209. párr. 157.

58 Ver Caso Bámaca Velásquez vs. Guatemala, Sentencia de 25 de noviembre de 2000, Serie C No. 70; Caso La Cantuta vs. Perú, Sentencia de 30 de noviembre de 2007, Serie C No. 173; Caso Comunidad Indígena Sawhoyamaxa vs. Paraguay, Sentencia de 29 de marzo de 2006, Serie C No. 146; Caso del Pueblo Saramaka vs. Surinam, Sentencia de 12 de agosto de 2008, Serie C No. 185; Caso de las Niñas Yean y Bosico vs. República Dominicana, Sentencia de 8 de septiembre de 2005, Serie C No. 130; Caso Trujillo Oroza vs. Bolivia, Sentencia de 26 de enero de 2000, Serie C No. 64; y Caso Benavides Cevallos vs. Ecuador, Sentencia de 19 de junio de 1998, Serie C No. 38.

59 Caso Bámaca Velásquez vs. Guatemala, Sentencia de 25 de noviembre de 2000, Serie C No. 70, párr. 179-181; Caso La Cantuta vs. Perú, Sentencia de 30 de noviembre de 2007, Serie C No. 173 párr. 121, y Caso Ticona Estrada y otros vs. Bolivia, Sentencia de 27 de noviembre de 2008, Serie C No. 191, párr. 71. Por otra parte, en dos casos la Corte declaró la violación del artículo 3 de la Convención con base en el allanamiento del Estado a la violación de esa disposición: caso Benavides Cevallos vs. Ecuador, Sentencia de 19 de junio de 1998, Serie C No. 38, párr. 43 y caso Trujillo Oroza vs. Bolivia, Sentencia de 26 de enero de 2000, Serie C No. 64, párr. 41.

60 Caso Radilla Pacheco, párr. 156; Caso Anzualdo Castro, párr. 88; Caso del Pueblo Saramaka, párr. 166; Caso Comunidad Indígena Sawhoyamaxa, párr. 188 y Caso Yean y Bosico, párr. 179. Ver también la descripción del contenido del derecho al reconocimiento de la personalidad jurídica expuesta en el caso Bámaca Velásquez vs. Guatemala, supra nota 3, párr. 179.

61 Entre los cuestionamientos que se formulan, destacan algunos votos razonados de jueces de la Corte IDH, tales como los pronunciados por los jueces De Roux Rengifo y García Ramírez en el Caso Bámaca Velásquez vs. Guatemala. Asimismo, el Juez García Ramírez expuso nuevamente sus críticas a dicha interpretación en su voto razonado del Caso Anzualdo Castro vs. Perú, Sentencia de 22 de septiembre de 2009, Serie C No. 202, párr. 31. En éste señaló “¿Estamos hablando, pues, del desconocimiento de la personalidad jurídica, con todo lo que ésta significa, o estamos aludiendo a la extrema, gravísima obstrucción del ejercicio de los derechos, que incuestionablemente existe en la desaparición forzada? De ser esto último, se ataca el ejercicio de derechos cuya titularidad -prenda de la personalidad jurídica- se mantiene en el haber de la persona que ha desaparecido $[\ldots]^{\prime \prime}$. 
En vista de esto, resulta pertinente formular algunas precisiones: primero, efectivamente el derecho al reconocimiento de la personalidad jurídica no comprende la denominada capacidad de ejercicio, entendida ésta como la habilitación necesaria para ser contraer derechos y obligaciones por vía de la actuación contractual y extracontractual ${ }^{62}$. Segundo, ello no significa que el mentado derecho no guarde ninguna conexión con el ejercicio de otros derechos. Por el contrario, la propia Corte IDH ha admitido que el reconocimiento del derecho de la personalidad jurídica "representa un parámetro para determinar si una persona es titular o no de los derechos de que se trate, y si los puede ejercer" y que "es necesario el reconocimiento de la personalidad jurídica [...] para el goce de otros derechos, como el derecho a la vida y a la integridad personal"63. En este sentido, la falta o negativa del reconocimiento de la personalidad jurídica conlleva la imposibilidad de ejercer todos los restantes derechos, tanto por el propio titular como por otras personas actuando en su favor.

Resulta plausible admitir que los casos de desapariciones forzadas, en las condiciones precedentemente expuestas, presentan una relevante dimensión que no queda comprendida ni bien explicada en la sola imposibilidad de gozar o ejercer diversos derechos ${ }^{64}$. Aquellos casos presentan una particular situación, dado que aún cuando formalmente el Estado no ha desconocido la personalidad jurídica de la persona desaparecida, por las circunstancias fácticas que caracterizan este crimen, la víctima en cuestión queda en un estatus muy similar a la inexistencia legal. Por una parte, nadie sabe donde se encuentra, ni en qué condiciones, ni si continúa viva o ha muerto. Ningún registro oficial o autoridad proporciona esa información y el Estado no realiza ninguna actividad destinada a resolver esas interrogantes o incluso obstaculiza su resolución. Consecuentemente, los esfuerzos de terceras personas destinados a cautelar los derechos del desaparecido son infructuosos $y$, finalmente, se acredita que todo ello es imputable al propio aparato estatal, que ha llevado a cabo su desaparición y dispuesto los medios para impedir su hallazgo o amparo. En definitiva, a partir de un determinado momento de la vida de esa persona, el ordenamiento jurídico pareciera dejar de tutelar su existencia y tanto el Estado como la sociedad pierden todo vínculo o forma de reconocimiento respecto a ese sujeto.

Las últimas sentencias de la Corte Interamericana en la materia, dan cuenta de un claro esfuerzo por reconocer esa particularidad de las desapariciones forzadas, a través de la aplicación del artículo $3^{65}$.

Sin embargo, esta dificultosa -o incluso forzosa- aplicación del derecho consagrado en el artículo 3 de la Convención no es la única alternativa normativa para afrontar las complejidades y pecu-

62 Ver NOWAK, Manfred. U.N. Convenant on Civil and Political Rights: CCPR Commentary. Kehl am Rhein. Strasbourg, Arlington, Engel, 1993, pp. 282-283. Según este autor, en el ámbito del sistema universal, la confusión podría remontarse a los trabajos preparatorios del Pacto de Derechos Civiles y Políticos y a la cercanía que en principio tuvo el artículo 16 de dicho instrumento con el artículo 6 de la Convención Europea de Derechos Humanos. La historia de esta disposición indica que se consideró que el reconocimiento de la personalidad jurídica debía ir acompañado de la garantía de diversos derechos privados, como celebrar contratos, adquirir propiedad, aceptar empleo y contraer matrimonio, entre otros.

63 Caso del Pueblo Saramaka vs. Surinam, párr. 168 y Caso Comunidad Indígena Sawhoyamaxa vs. Paraguay, párr. 190. La Corte IDH también se ha pronunciado respecto de la diferencia entre capacidad de goce y de ejercicio y su relación con el derecho a la personalidad jurídica en Condición Jurídica y Derechos Humanos del Niño, Opinión Consultiva OC17/02 del 28 de agosto de 2002, Serie A No. 17, párr. 41. Ver también en dicha Opinión Consultiva el voto concurrente del juez Cançado Trindade, párr. 6-8.

64 Ya en el caso Bámaca Velásquez vs. Guatemala, el juez Roux Rengifo reconocía en su voto razonado que “Detrás de la pregunta recurrente sobre si la desaparición forzada de personas viola el derecho al reconocimiento de la personalidad jurídica, se encuentra, entre otras preocupaciones, la referente al hecho de que ciertos aspectos, muy agresivos y ofensivos, de la correspondiente conducta, no quedan cubiertos por la órbita de las disposiciones referentes a los derechos a la libertad, la integridad y la vida".

65 Caso Anzualdo Castro, párr. 89. 
liaridades que nos presentan las desapariciones forzadas. Aquellas más bien parecen reafirmar la necesidad y conveniencia de abordar este fenómeno en el marco de instrumentos especializados capaces de recoger, precisamente, aquellas particularidades que pueden rebasar el alcance de las disposiciones de un tratado general sobre derechos humanos ${ }^{66}$.

\section{c. Derechos políticos (Artículo 23 de la Convención Americana sobre Derechos Humanos)}

En el caso Chitay la Corte analizó, entre otras materias, cómo el patrón de hostigamiento que sufrieron los líderes indígenas Mayas en el contexto de la aplicación de la "Doctrina de la Seguridad Nacional" en Guatemala, afectó el ejercicio de los derechos políticos del señor Florencio Chitay -víctima de desaparición forzada- y su impacto en la comunidad a la que representaba ${ }^{67}$.

La Corte reiteró lo ya expresado en el caso Yátama ${ }^{68}$ al señalar que los Estados tienen la obligación de garantizar el pleno goce de los derechos políticos sin discriminación y que "debe[n] adoptar las medidas necesarias para garantizar su pleno ejercicio [...], considerando la situación de debilidad o desvalimiento en que se encuentran los integrantes de ciertos sectores o grupos sociales" 69 . Agregó que los derechos políticos "propician el fortalecimiento de la democracia y el pluralismo político" y que su pleno goce implica "que los ciudadanos tienen no sólo el derecho sino también la posibilidad de participar en la dirección de los asuntos públicos" ${ }^{\prime 70}$.

El pleno goce de este derecho individual cumple una función supra convencional para la Corte, que se relaciona con el interés de la Comunidad de ser representada ante las autoridades. Al respecto señaló que:

“[...] la comunidad se vio privada de la representación de uno de sus líderes en diversos ámbitos de su estructura social, y principalmente en el acceso al ejercicio pleno de la participación directa de un líder indígena en las estructuras del Estado, donde la representación de grupos en situaciones de desigualdad resulta ser un prerrequisito necesario para la realización de aspectos fundamentales como la inclusión, la autodeterminación y el desarrollo de las comunidades indígenas dentro de un Estado plural y democrático" ${ }^{\prime 71}$.

La situación de vulnerabilidad de ciertos sectores ha conducido a la Corte a solicitar a los Estados que garanticen que:

"[...] los miembros de las comunidades indígenas y étnicas [...] puedan participar en la toma de decisiones sobre asuntos y políticas que inciden o pueden incidir en sus derechos y en el desarrollo de dichas comunidades, de forma tal que puedan integrarse a las instituciones y órganos estatales y participar de manera directa y proporcional a su población en la dirección de los asuntos públicos [...] y de acuerdo a sus valores, usos, costumbres y formas de organización"72.

\footnotetext{
66 CENTRO DE DERECHOS HUMANOS, Facultad de Derecho, Universidad de Chile. Boletín de Jurisprudencia de la Corte Interamericana de Derechos Humanos 3/2009. Disponible en http://www.estadodederechocdh.uchile.cl/media/ noticias/boletin_3.pdf

67 Caso Chitay Nech y otros vs. Guatemala. Sentencia de 25 de mayo de 2010. Serie C No 212 párr. 108.

68 Caso Yatama vs. Nicaragua. Excepciones Preliminares, Fondo, Reparaciones y Costas. Sentencia de 23 de junio de 2005. Serie C No. 127, párr. 201.

69 Caso Chitay Nech, párr. 106.

70 Ibídem, párr. 107.

71 Ibídem párr. 113.

72 Ibídem, párr. 114. Esa cita también puede encontrarse en el Caso Yátama, párr. 225.
} 
Este criterio es el que se encuentra tras la decisión de la Corte de declarar en el caso Yatama que exigir a los miembros de comunidades indígenas el participar únicamente a través de partidos políticos constituía:

"[...] una restricción indebida al ejercicio de un derecho político, que implica un límite innecesario al derecho a ser elegido, tomando en cuenta las circunstancias del presente caso, a las que no son necesariamente asimilables todas las hipótesis de agrupaciones para fines políticos que pudieran presentarse en otras sociedades nacionales o sectores de una misma sociedad nacional"73.

Resulta claro que para la Corte el criterio de cumplimiento de parte de los Estados de sus obligaciones respecto de los derechos políticos, tratándose de los grupos históricamente vulnerables, se traduce en la garantía de una participación política efectiva. Por supuesto, esta interpretación está en línea con el principio de interpretación pro persona y jurisprudencia constante de la Corte en el sentido de que no basta con un goce nominal de los derechos, sino el pleno ejercicio de éstos ${ }^{74}$.

La aplicación de este criterio debe ser contrastado por lo resuelto por la Corte en el caso Castañeda Gutman ${ }^{75}$ del año 2008, donde decidió que para efectos de participar en las elecciones, el requisito de pertenecer a un partido político constituía una restricción legítima. Sobre los requisitos que legítimamente un Estado podría solicitar para la participación política indicó que,

"Siempre que no sean desproporcionados o irrazonables, se trata de límites que legítimamente los Estados pueden establecer para regular el ejercicio y goce de los derechos políticos y que se refieren a ciertos requisitos que las personas titulares de los derechos políticos deben cumplir para poder ejercerlos" ${ }^{\prime 76}$.

En síntesis, tratándose de miembros de las comunidades indígenas y étnicas la Corte estima que la exigencia de participar a través de partidos políticos constituye una restricción ilegítima, pues considera como un elemento determinante para garantizar la efectiva participación política el reconocimiento de sus valores, usos, costumbres y formas de organización. En cambio, para quienes no pertenecen a comunidades indígenas y étnicas, la exigencia de participar a través de partidos políticos sí sería legítima, pues no sería una medida desproporcionada o irracional. Una forma de interpretar esta posible contradicción, es considerar que para efectos de asegurar el pleno goce de derechos de las personas en uno y en otro caso deben hacerse a través de diferentes medios, siendo la exigencia de pertenecer a un partido político idónea para algunas hipótesis y para otras no. Pero esto es difícil de sostener, ya que -regresando a la decisión de la Corte en el caso Castañeda-, esto supondría no solo que hay un objetivo legítimo para restringir los derechos políticos fuera del artículo 23, sino que además, este requisito en algunos casos sería un requisito estricto, y en otros, laxo. Sin duda esto nos devuelve a la idea de que la Corte debiera optar por una interpretación estricta en casos de restricciones, más aún cuando la propia Convención es clara al efecto en su artículo 23.2 que establece que "la ley puede reglamentar el ejercicio de los derechos y oportunidades a que se refiere el inciso anterior, exclusivamente por razones de edad, nacionalidad, residencia, idioma, instrucción, capacidad civil o mental, o condena, por juez competente, en proceso penal"77.

73 Caso Yátama, párr. 219.

74 Caso Velásquez Rodríguez Vs. Honduras. Excepciones Preliminares. Sentencia de 26 de junio de 1987. Serie C No. 1.

75 Caso Castañeda Gutman Vs. México. Excepciones Preliminares, Fondo, Reparaciones y Costas. Sentencia de 6 de agosto de 2008. Serie C No. 184, párr. 155.

76 Idem. Énfasis añadido.

77 Convención Americana sobre Derechos Humanos, artículo 23.2. (Énfasis añadido). Para revisar este punto en mayor profundidad ver NASH, Claudio y SARMIENTO, Claudia. Reseña de la jurisprudencia de la Corte Interamericana de Derechos Humanos (2008). Anuario de Derechos Humanos 2009 (5): 123-133. 
Más allá de esta discusión, será interesante constatar en el futuro cómo interpretará la Corte las medidas que debe adoptar la participación política efectiva y cuáles serán desproporcionadas o irrazonables, y cómo se complementan ambos criterios tratándose de personas que no pertenecen a comunidades indígenas y étnicas, pero a quienes de todas formas debe garantizárseles el pleno ejercicio y goce de sus derechos políticos.

\section{d. Protección de la Honra y la Dignidad (vida privada) / Integridad personal}

En los casos Fernández Ortega y Rosendo Cantú la Corte analizó cómo la violación sexual afecta el pleno goce del derecho a la Protección de la Honra y la Dignidad, consagrado en el artículo 11 de la Convención Americana. La Corte indico que éste "incluye, entre otros, la protección de la vida privada. Por su parte, el concepto de vida privada es un término amplio no susceptible de definiciones exhaustivas, pero que comprende, entre otros ámbitos protegidos, la vida sexual y el derecho a establecer y desarrollar relaciones con otros seres humanos" ${ }^{\prime 78}$. La Corte señaló que la violación sexual "vulneró valores y aspectos esenciales de su vida privada, supuso una intromisión en su vida sexual y anuló su derecho a tomar libremente las decisiones respecto con quien tener relaciones sexuales, perdiendo de forma completa el control sobre sus decisiones más personales e íntimas y sobre las funciones corporales básicas"79.

A partir de esta definición de la vida privada, la Corte delimitó un área en la que cada persona, lícitamente, puede decidir libre de intromisiones cómo, cuándo y con quién vivir la sexualidad. Es decir, la Corte esbozó una noción de autonomía sexual. Más aún, profundizó en esta línea de razonamiento al indicar que "la protección de la vida privada, la vida familiar y el domicilio implica el reconocimiento de que existe un ámbito personal que debe estar exento e inmune a las invasiones o agresiones abusivas o arbitrarias por parte de terceros o de la autoridad pública. En este sentido, el domicilio y la vida privada y familiar se encuentran intrínsecamente ligados, ya que el domicilio se convierte en un espacio en el cual se puede desarrollar libremente la vida privada y la vida familiar" 80 .

La Corte no sólo legitima la existencia de una autonomía sexual, sino que también la relaciona con las condiciones materiales que hacen posible su goce ${ }^{81}$, esto es, la protección del domicilio ${ }^{82}$. Particularmente, en el goce de una autonomía sexual, elementos como el acceso a la información y a prestaciones de salud, además de la prohibición de coacción, determinan que cada persona pueda realmente actuar en conciencia, de manera libre e informada.

De la misma forma, es plausible considerar que la construcción de un espacio para la decisión autónoma sobre la sexualidad, eventualmente, incluye las decisiones sobre la reproducción, pues ésta es una consecuencia del ejercicio de la primera. En este sentido, la discusión acerca de los límites del ejercicio de esta autonomía puede enfocarse en los supuestos bajo los cuales

78 Caso Fernández Ortega, párr. 129.

79 Ibídem.

80 Ibídem, párr. 157. Énfasis añadido.

81 Para una mirada a la noción de autonomía en general se sugiere BUSS, Sarah. Personal Autonomy. The Stanford Encyclopedia of Philosophy (Fall 2008 Edition), ZALTA, Edward N. (ed.) Consulta en línea 21 de marzo de $2011<$ http:// plato.stanford.edu/archives/fall2008/entries/personal-autonomy/>. Una revisión de su importancia en el contexto de las decisiones políticas de individuos y colectividades, ver CHRISTMAN, John. Autonomy in Moral and Political Philosophy. The Stanford Encyclopedia of Philosophy (Spring 2011 Edition). Zalta, Edward N. (ed.) Consulta en línea 21 de marzo de 2011 <http://plato.stanford.edu/archives/spr2011/entries/autonomy-moral/>.

82 Sobre las condiciones materiales que deben rodear el ejercicio de la autonomía sexual ver CONSEJO INTERNACIONAL DE POLÍTICAS DE DERECHOS HUMANOS. Ginebra, Suiza. Sexualidad y Derechos Humanos, 2010. Disponible en http://www.ichrp.org/files/reports/57/137_report_es.pdf 
puede resultar lícito que el Estado intervenga en la autonomía reproductiva de una persona, pero no sería admisible cuestionar si ésta existe o si es legítimo su ejercicio. Un marco idóneo para discutir el alcance de dicha ponderación es el que ofrecen las reglas del artículo 29 de la propia Convención Americana ${ }^{83}$.

Si bien en los casos Fernández Ortega y Rosendo Cantú la Corte, claramente, estaba haciendo referencia a la ilicitud del uso de la fuerza, lo cierto es que este razonamiento abre las puertas para revisar si existen interferencias en este ámbito que, aunque no violentas, puedan ser consideradas igualmente ilegítimas. Esta posibilidad cobra particular fuerza si se considera que la Corte ha ligado la protección de la vida privada al espacio de la vida familiar. Este puede ser un punto especialmente relevante tratándose de las interferencias que legal o fácticamente encuentran las parejas de homosexuales y lesbianas en el ejercicio de su sexualidad y en el debate sobre el cuidado personal de sus hijas/os ${ }^{84}$. Más aún, si admitimos que todos los derechos y libertades reconocidos en la Convención deben ser garantizados a toda persona "[...] sin discriminación alguna por motivos de raza, color, sexo, idioma, religión, opiniones políticas o de cualquier otra índole, origen nacional o social, posición económica, nacimiento o cualquier otra condición social" 85 .

83 Artículo 29. Normas de Interpretación. Ninguna disposición de la presente Convención puede ser interpretada en el sentido de: (a) permitir a alguno de los Estados partes, grupo o persona, suprimir el goce y ejercicio de los derechos y libertades reconocidos en la Convención o limitarlos en mayor medida que la prevista en ella; (b) limitar el goce y ejercicio de cualquier derecho o libertad que pueda estar reconocido de acuerdo con las leyes de cualquiera de los Estados partes o de acuerdo con otra convención en que sea parte uno de dichos Estados; (c) excluir otros derechos y garantías que son inherentes al ser humano o que se derivan de la forma democrática representativa de gobierno, y (d) excluir o limitar el efecto que puedan producir la Declaración Americana de Derechos y Deberes del Hombre y otros actos internacionales de la misma naturaleza.

84 Por ejemplo, ver CIDH. Karen Atala e hijas (demanda). Caso 12.502 contra la República de Chile. 17 de septiembre de 2010.

85 Artículo 1.1. de la Convención Americana sobre Derechos Humanos. 